\title{
An Assessment of Canadian Criminalized Women's Health Information Preferences and Health Literacy Skills
}

\author{
Lorie Donelle, $^{1, *}$, Ebony Rempel ${ }^{1}$, Jodi Hall ${ }^{2}$ \\ ${ }^{1}$ Faculty of Health Sciences, Arthur Labatt Family School of Nursing/School of Health Studies, Western University, Canada \\ ${ }^{2}$ School of Nursing, Fanshawe College, Canada
}

Copyright (C) 2016 by authors, all rights reserved. Authors agree that this article remains permanently open access under the terms of the Creative Commons Attribution License 4.0 International License

\begin{abstract}
This research assessed criminalized women's health literacy skills. Health literacy is conceptualized as one's ability to access, understand, appraise, communicate, and act upon health information. Estimates of health literacy skill for criminalized women in Canada do not exist. The research question that guided this study was: what are the assessed health literacy skills of criminalized women? A cross-sectional survey design assessed participant demographics, health information preferences, and health literacy skills. The Newest Vital Sign (NVS) was administered to incarcerated women in Ontario, Canada. Descriptive statistics of demographic data and assessed health literacy skills were reported. Eighty-five women with a mean age of 29 years participated. The majority $(\mathrm{N}=50$, $65 \%$ ) reported an income less than $\$ 14,999$ (CAN) and $81 \%$ $(\mathrm{N}=68)$ reported their education level as a high school diploma or less. A range of health literacy skill [inadequate (51\%), marginal (15\%), adequate $(34 \%)]$ were documented with a mean NVS score of $2.79 \pm 1.75 / 6$. The results demonstrated participants' had limited health literacy skills, which have far reaching implications for the development of health resources that strive to accommodate diverse health literacy skill and lived complexity. The results support population level reports of limited health literacy skill among marginalized Canadians.
\end{abstract}

Keywords Criminalized Women, Health Literacy, Women's Health, Health Promotion

\section{Introduction}

The life context of criminalized women exemplifies existing health inequities, outlined by the World Health Organization (WHO) as important determinants of health [1]. The fastest growing criminalized population worldwide is women; overrepresented are women who are racialized,
Aboriginal, young, are living in poverty, have low literacy levels, who experience multiple health concerns, and have mental and cognitive disabilities [1-4]. Admissions to correctional settings adds a tremendous burden to the challenges already experienced by these women. Furthermore upon release from incarcerated settings, criminalized women are often returning to poor and unsafe housing, and lack meaningful employment opportunities $[5,6]$. Consequently, criminalized women's lives are characterized as being perpetually unstable, exacerbating the difficulties they face accessing and utilizing timely and appropriate health information and services within their communities $[1,2]$.

The challenges criminalized women face accessing appropriate health care services is further complicated by the present context of health care delivery. That is, to effectively engage with health care systems and to respond to the increasing demands for personal accountability for self-health promotion, individuals require adequate health literacy skills $[7,8]$. Health literacy has been defined as "[t]he ability to access, understand, evaluate and communicate information as a way to promote, maintain and improve health in a variety of settings across the life-course" [8, p. 11]. Key outcomes of enhanced health literacy may include informed health care decision-making, self-efficacy and improved personal empowerment $[6,9,10]$.

\subsection{Literacy and Health Literacy Skills}

Within Canada, almost half of all adults function below the expected minimum literacy level, and are challenged by increasingly complex material [11]. A reported $60 \%$ of Canadians have limited health literacy skills [12]. On average, people with limited health literacy skills tend to have low socioeconomic backgrounds, have increased health problems, live in poverty, have fewer years of education, experience greater chronic disease, and use less disease prevention services [13-15]. Current literature indicates that 
limited literacy skills are linked to a declining use of available health information and services, and are associated with poorer health outcomes and health status than individuals with adequate health literacy skills $[10,12,16]$. Individuals with adequate health literacy skills have reported better self-care practices, improved disease state knowledge, greater coping skills and engage in healthier lifestyle practices [17-19]. Within contemporary health care settings the ability to access and appraise online health resources is increasingly vital [20]. In fact, approximately $70 \%$ of North American adults search for health information online [21,22] which highlights the need for proficiency in computer and Internet use, and the capacity to appraise complex, and often contradictory online information $[20,23]$.

\subsection{Literacy and Health Literacy within Incarceration Populations}

Estimates within the prison population in Canada indicate that $70 \%$ of individuals read below an $8^{\text {th }}$ grade skill [24]. Estimated literacy skills within the U.S. prison population taken from the 2003 National Assessment of Adult Literacy Prison Survey indicated that $50 \%$ of criminalized women had basic or below basic document literacy scores, $85 \%$ had basic or below basic numeracy scores and $58 \%$ had basic or below basic prose literacy scores [25].

Currently there is insufficient evidence regarding the health literacy skills of criminalized women who tend to have more complex health concerns, experience significantly greater barriers to health care resources, and have higher mortality and morbidity rates relative to the general population $[1,2,4,5,24]$. To date, there has been limited investigation of health literacy skills among incarcerated populations and particularly among criminalized women in Canada. Therefore the purpose of this research was to assess the health literacy skills of criminalized women incarcerated within a provincial detention facility to establish a baseline measure upon which future interventions could be measured against. The research question that guided this study was what are the assessed health literacy skills of criminalized women?

\section{Materials and Methods}

A cross-sectional design was used to investigate health literacy skills of criminalized women within a provincial detention facility. The study protocol was approved by institutional (university and provincial government) research ethics review boards.

\subsection{Participant Recruitment}

Participants were recruited from a single provincial detention facility in Southwest Ontario, Canada. A detention facility was chosen as the site for data collection in part because of the limited attention to provincial relative to federal correctional settings. Participant recruitment was facilitated through partnering with the detention facility's health services department and correctional staff of the women's unit. Sample size calculation indicated a minimum of 65 participants as appropriate [26]. Using a convenience sampling strategy [27], participants agreeable to participating in the research were recruited with support of the facility's health services administration.

\subsection{Data Collection}

All data was collected in a locked room in the women's unit within the incarcerated setting. Individuals were included in the study if they fit the following criteria: (1) 18 years of age or older, (2) housed in the women's unit of the correctional facility, (3) in custody at the time of data collection, and (4) could speak English. A letter of information about the study was provided to and read aloud with women and consent to participate was obtained. Collected data included a demographic survey, a health information survey, and the Newest Vital Sign survey (NVS) [28] which assessed health literacy (prose and numeric) skills. The administration of the demographic, health information, and the NVS surveys had an approximate time commitment of 20 minutes per participant.

\subsection{Data Collection Instruments}

\subsubsection{Demographic Survey}

The collected demographic data included participants' age, marital status, number of children, income source, alleged offence / reason for incarceration, level of income, highest attained level of education, place of birth, primary and preferred language.

\subsubsection{Health Information Survey}

Participants were asked about their health information needs, and to indicate how, where and for which health issues they would seek information. Participants ranked their most preferred sources of health information. The choices given were: television, radio, magazines / newspaper, pamphlets / brochures, Internet, family / friends, health care providers and "other" sources. Investigation into participants' online health information access, included questions regarding participants' ability to access a computer / smartphone and about their access to the Internet in the community as well as in the detention facility. Participants were also asked how often they searched the Internet for health information and what kinds of health information / health information topics they searched for. Participants recorded their top three health topics that they searched for online.

\subsubsection{Assessment of Functional Health Literacy}

Weiss et al. [28] developed the Newest Vital Sign (NVS), a standardized assessment of health literacy, measuring participant's ability to read, listen to instructions and apply 
information. The NVS consists of six assessment questions contextualized to information on a nutrition label [visual prop]. Sample questions include: (1) If you eat the entire container (of ice cream), how many calories will you eat?, and (2) If you usually eat 2500 calories in a day, what percentage of your daily value of calories will you be eating if you eat one serving?. Participants scored one point for each correct answer with a response range of 0-6 with higher scores indicating a higher degree of health literacy. Scores between 0-2 typically demonstrate inadequate health literacy skills; individuals with a score of 3 have marginal health literacy; individuals with scores $4-6$ have adequate health literacy skills. The NVS has good psychometric properties with good internal consistency, and good face and criterion validity [28]. This assessment was chosen because of administrative brevity and because the instrument captures both prose and numeric health literacy skills.

\subsection{Data Analysis}

All analyses were performed using the statistical analysis software program SPSS (version 22) [29]. Descriptive statistics and demographic data of health literacy measures were reported.

\section{Results}

In total, 85 women participated in this study, with a mean age of 29 years (range $18-53$ years). Most $(63 \%, n=53)$ women were single or never married. The majority $(65 \%, \mathrm{n}=$ 50) reported an income of less than $\$ 14,999$. Of all the women who participated in this study $81 \%(\mathrm{n}=68)$, reported having a high school diploma or less education. Women were charged with a variety of crimes (e.g., theft, robbery, breach of probation, drug and weapon related charges, driving related charges and assault). Table 1 provides a summary of the descriptive statistics.

In addition to demographic information, participants in this study were asked how they searched for health information, and their health information preferences. The choice of information sources included: television, radio, magazines / newspapers, pamphlets / brochures, Internet, family / friends, health care providers and other sources. Participant's preferred sources of health information were: health care providers $(n=38,46 \%)$, the Internet $(n=20,25 \%)$, family / friends $(n=14,17 \%)$, pamphlets / brochures $(n=10$, $12 \%)$ and television $(\mathrm{n}=8,9 \%)$. Although access to computers and the Internet was prohibited while in custody, $95 \%$ of participants reported having access to a computer and $99 \%$ reported access to the Internet within community. The majority of participants $(\mathrm{n}=52,61 \%)$ reported searching the Internet one or more times per month for health related information, on a variety of health related issues; most frequently mentioned were issues of sexual health, use of illicit drugs, nutrition / weight management, and maternal child health (see Table 2).

Table 1. Demographic Statistics of Criminalized Women $(\mathrm{N}=85)$

\begin{tabular}{|c|c|c|}
\hline Age (years) & $\mathrm{N}=85$ & \\
\hline Mean & 29.44 & \\
\hline \multirow[t]{2}{*}{ Range } & $18-53$ & \\
\hline & $\mathbf{N}$ & $\%$ \\
\hline \multicolumn{3}{|l|}{ Marital Status } \\
\hline Single & 53 & 63 \\
\hline Married & 6 & 7 \\
\hline Separated/Divorced & 16 & 19 \\
\hline Other & 9 & 11 \\
\hline \multicolumn{3}{|l|}{ Number of Children } \\
\hline $0-3$ & 78 & 93 \\
\hline $4-6$ & 6 & 7 \\
\hline \multicolumn{3}{|l|}{ Level of Income } \\
\hline Less than $\$ 14,999$ & 50 & 65 \\
\hline$\$ 15,000$ to $\$ 34,999$ & 21 & 27 \\
\hline$\$ 35,000$ to $\$ 54,999$ & 2 & 3 \\
\hline$\$ 55,000$ to $\$ 99,999$ & 3 & 4 \\
\hline More than $\$ 100,000$ & 1 & 1 \\
\hline \multicolumn{3}{|l|}{ Level of Education } \\
\hline Elementary & 7 & 8 \\
\hline Some high school & 43 & 51 \\
\hline High school diploma & 18 & 22 \\
\hline $\begin{array}{c}\text { College/trade school } \\
\text { diploma / some university }\end{array}$ & 16 & 17 \\
\hline Bachelor Degree & 0 & 0 \\
\hline \multicolumn{3}{|l|}{ Place of Birth } \\
\hline Canada & 80 & 95 \\
\hline Other & 4 & 5 \\
\hline \multicolumn{3}{|l|}{ Primary Language } \\
\hline English & 82 & 98 \\
\hline Other & 2 & 2 \\
\hline \multicolumn{3}{|l|}{ Preferred Language } \\
\hline English & 83 & 100 \\
\hline Other & 0 & 0 \\
\hline
\end{tabular}


Table 2. Participants' Health Information Topics of Interest

\begin{tabular}{|c|c|c|}
\hline $\begin{array}{l}\text { Health Information Topics } \\
\text { Searched }\end{array}$ & $\begin{array}{l}\text { Women seeking online information by topic: } \\
\text { health topic reported within the top } 3 \text { priority } \\
\text { information needs by women }\end{array}$ & Specific examples of Topics \\
\hline Sexual Health & 49 & $\begin{array}{c}\text { Hepatitis C } \\
\text { STDs } \\
\text { STIs } \\
\text { HIV, AIDS } \\
\end{array}$ \\
\hline Maternal child health & 20 & $\begin{array}{c}\text { Pregnancy } \\
\text { Child's health } \\
\text { In vitro fertilization }\end{array}$ \\
\hline Nutrition and Weight & 20 & $\begin{array}{c}\text { Recipes } \\
\text { Weight management } \\
\text { Exercising } \\
\end{array}$ \\
\hline Illicit drug Use & 20 & $\begin{array}{l}\text { Drug Addiction } \\
\text { Methadone } \\
\text { Safe Needle Use } \\
\end{array}$ \\
\hline Mental Health & 19 & $\begin{array}{l}\text { Depression } \\
\text { ADHD } \\
\text { Bipolar } \\
\end{array}$ \\
\hline Infectious Diseases & 12 & $\begin{array}{l}\text { Spreading of diseases } \\
\text { Germs } \\
\text { Colds }\end{array}$ \\
\hline Cancer & 11 & $\begin{array}{c}\text { Cervical Cancer } \\
\text { Breast Cancer }\end{array}$ \\
\hline Medication & 8 & $\begin{array}{c}\text { Immunizations / shots } \\
\text { Drug interactions }\end{array}$ \\
\hline Diabetes & 5 & Diabetes self-management \\
\hline Other & 45 & $\begin{array}{c}\text { Mouth disease } \\
\text { Flesh Eating disease } \\
\text { Migraines } \\
\text { Osteoporosis } \\
\text { Foot care } \\
\text { Chest Pain } \\
\text { Prevention against all diseases } \\
\text { Looking for a doctor } \\
\text { Psoriasis }\end{array}$ \\
\hline
\end{tabular}

\subsection{Health Literacy Profile of Criminalized Women}

The mean health literacy score of participants was 2.79 (SD 1.75). Cronbach's alpha for the NVS items was acceptable at 0.68 . An average health literacy score of 2.79 reflects inadequate health literacy skill. Scores between 0-2 demonstrate inadequate health literacy skills, a score of 3 demonstrates marginal health literacy skills, and scores between 4-6 demonstrate adequate health literacy skills [28]. Fifty one percent of the participants $(n=42)$, had inadequate health literacy skills, $15 \%(\mathrm{n}=12)$ had marginal health literacy skills and $34 \%(n=28)$ had adequate health literacy skills. Sixty-six percent $(n=54)$ of women in this study would be challenged in terms of their ability to access, understand, appraise and / or act on health information to inform decisions about their health (e.g., reading medication instructions, understanding nutrition labels) [28].

\section{Discussion}

This study investigated the health literacy skills of women incarcerated within a provincial detention facility in Canada. To our knowledge, this work represents the first reported assessment of health literacy skills (information seeking, prose and numeracy skills) among criminalized women. In light of this, investigating criminalized women's health literacy skills provides an initial baseline measurement. This assessment serves as a point of reference for the development of health literacy skills, and lends critical insights to be considered for future health resource creation and improvements within and among this disenfranchised population of women. While the assessed health literacy skills of women who participated in this study revealed a continuum of skills, the majority of participants $(66 \%)$ demonstrated inadequate or marginal prose and numeric health literacy skills. This is not surprising given the reported $60 \%$ of Canadians that have limited health literacy skills [12] and the estimates within the prison population in Canada that indicate that $70 \%$ of individuals read below an $8^{\text {th }}$ grade skill level [24]. This is distressing in light of the significant challenges faced by low health literate Canadians who lack the skills that support informed decision-making regarding their own health care and exacerbated by a low health literate system $[12,30]$.

The findings of low health literacy among the majority of participants in this study has significant implications for 
criminalized women in terms of assessing their risk of ill health, engaging in preventive screening, describing symptoms of ill health / disease, following medication / treatment directions and correctly calculating doses of medication $[12,30]$. However, women in this study sought information on a wide range of health matters. Information seeking for sexual health issues was most frequently reported, with maternal and child health inquiries (i.e. nutrition), weight management, illicit drug use, and mental health concerns following as topics of interest to participants. These findings align with earlier reported research where the majority of health concerns expressed by criminalized women related to pregnancy, sexually transmitted infections, and mental health concerns [31-32]. Specifically, Bernier and McLelland [33] assessed the health status and use of health services of women detained in a provincial correctional centre in Canada. These women experienced health concerns related to sexual health, stress, anxiety, nutrition and weight / physical activity; infectious diseases (e.g., Hep C) and reported use of illicit and prescription drugs, and alcohol [33]. The health information seeking behaviours of the women in this study aligns with assessed health concerns among criminalized women in similar studies. The information seeking behaviour reflects women's endeavors at self-care, particularly with regard to health issues that are typically stigmatized [34].

Studies have indicated that women go online to find and hear from others who are experiencing similar health concerns [21], and to search for information related to stigmatized illnesses (e.g., mental health issues, sexually transmitted infections). Berger et al. [35] indicated that people with stigmatized illness are significantly more likely to search the Internet for health information than those with non-stigmatized health concerns (e.g., heart problems, cancer and back pain). It is possible that the women in this study went online to search for health information preferring anonymity in light of the sensitive nature of the health information they sought. The Internet may also serve as a preferred source of health information in light of the difficulties in accessing health care among criminalized women [33] and the intolerant attitude from health care providers often reported by disenfranchised individuals [36-38]. Participants' reported information seeking behaviour, in spite of limited health literacy, highlights the need for appropriate and effective health interventions to enhance health literacy skills among criminalized women if they are to be equipped to assess and make meaningful use of health information.

Furthermore, researchers report that access to online health information may primarily advantage those that already benefit from greater income and higher education; potentially creating even larger differences in health disparities among different groups of people [15, 20, 39 40]. While almost all women in this study indicated Internet availability in their community, almost a quarter of the women reported that they never accessed the Internet.
Essential health literacy skills for online information seeking include: competency in using computers and the Internet, the ability to navigate through the complexity of online information and the knowledge and confidence to discern reliable from unreliable information [20,23,39]. An inquiry into why or the barriers to Internet access was not pursued within the scope of this investigation; this would be an important avenue for future research given the ubiquity of online health information seeking behaviour among the general Canadian population.

Research evidence suggests that individuals with inadequate or marginal health literacy skills may be precluded from accessing online health information or feel overwhelmed by the complexity of the information available online with much of the information written above an 8th grade reading level $[20,41]$. Apart from simply accessing the Internet, people with lower overall attained education are less likely to trust health information on the Internet [14]. In addition to the universal use of plain language skills to enhance information access, there is a need for health information that is composed and delivered in a way that aligns with the culture and context of the lives of criminalized women. Recognizing the Internet as an important health information resource, the implementation of policies and initiatives regarding free access to computers and the Internet where marginalized segments of the populations live and spend time (e.g., the downtown core in many communities) could support the women's health information needs [42]. A city in southwestern Ontario recently implemented a free outdoor Wi-Fi area available to all people within the downtown core of the city. London Area Wireless Network (LAWN) was started as a pilot project to test the use of a free Wi-Fi zone in London's downtown core [42]. It has become so popular that the zone has been expanded since the initial pilot was launched. This is one of Canada's largest free outdoor Wi-Fi hot spots [42]. Information on different community organizations offering support, services and access to computer and Internet use would be helpful to women on discharge from the detention centre into the community.

Access to health services can also be compromised; low health literate individuals often have difficulty locating healthcare facilities, applying for health benefits, and limited ability in providing informed consent $[12,30]$. The life context of criminalized women is further complicated by the health service access challenges inherent with limited health literacy skills. The significant health, social, economic, and educational challenges criminalized women negotiate are in direct opposition to the expected and even required knowledge, skills, and personal agency to effectively engage in decision making regarding personal self-health promotion and for their concerns to be taken seriously by providers [4].

Moreover, with the mounting expectation for effective self-health promotion and chronic disease management, there is a generalized assumption that health information seekers will have the ability to access and appraise online 
health resources [20]. However these assumptions need to be challenged in light of the assessed inadequate and marginal health literacy skills of the participants in this study.

Criminalized women are often stigmatized and marginalized within the health care system [36-38] for employing coping strategies (e.g., behaviors such as self-prescribed alcohol and drug (ab)use), and occupational choices (e.g., sex work) in response to a life history of disenfranchisement, and a chronic experience of limited opportunities, supports, and resources [5,6]. In fact, the limited education, income and health literacy skill of the women in this study may preclude them from attainting and securing safe and stable employment, and limit their ability to access services and / or participate positively in the community. Implications for health professionals include increased awareness and mindfulness of the implications of inadequate and marginal health literacy experienced by criminalized women. Enhancing the health literacy of providers and organizations is important to enhance individuals' success in accessing, understanding and using health information and services to enhance their health $[7,30]$. From a practice perspective, the results of this study should be sufficient to encourage public health care providers and organizations to focus attention on the health literacy skills and associated information and health services access behaviours of criminalized women [43].

Research is needed to examine individual approaches and institutional practices that support or hinder access to health information and services. Research into the preferred sources of health information and services particularly online information sources (e.g., government or social network sites) and online information search strategies of criminalized women is an area for future development.

\subsection{Limitations}

As with all research, this study had limitations. This research was conducted in English, therefore participants who lacked confidence in their English speaking ability were not included in this study. Including participants whose preferred language is not English may have resulted in different outcomes than those identified. As well, it may be that participants with poor literacy skills chose not to participate in the study. However, there was diverse range of assessed health literacy skills among the women who did participate.

\section{Conclusions}

Results from this study provide a baseline assessment of assessed health literacy skills among women incarcerated in a provincial detention facility within Canada. This research also contributes to the limited research literature on the health literacy skills of Canadian criminalized women and indicates that the majority of participants are limited in their ability to access, understand, evaluate and communicate information as a way to manage their health. This research has implications for the development of health resources that accommodates diverse health literacy skills and immense life complexity. Criminalized women would benefit from innovative health literacy educational programs [both in and outside of the incarcerated setting] and health education initiatives that support women's limited health literacy skills and enable more equitable access to health information and services.

\section{Acknowledgements}

The authors thank the women who participated in this study and appreciate the research support provided by the health services staff / administration and correctional staff at the provincial detention facility. This research was funded by the Social Sciences and Humanities Research Council (SSHRC).

\section{REFERENCES}

[1] World Health Organization. Women's health in prison: Correcting gender inequity in prison health. 2009.

[2] S. H. Friedman, M. D. Shelton, O. Elhaj, E. A. Youngstrom, D. J. Rapport, K. A. Packer, et al. Gender Differences in Criminality: Bipolar Disorder with Co-occurring Substance Abuse, J Am Acad Psychiatry Law. Vol 33, No.1, 188-195, 2005.

[3] S. Hayman, Imprisoning our sisters: The new federal women's prisons in Canada. Montreal: McGill-Queen's University Press, 1-298 2006.

[4] S. Pollack. Taming The Shrew: Regulating Prisoners Through Women-Centered Mental Health Programming. Crit Criminol, Vol.13, No.1, 71-87, 2005.

[5] S. Pollack. "You Can't Have it Both Ways": Punishment and Treatment of Imprisoned Women. J Progress Hum Serv, Vol.20, No.2, 112-28, 2009.

[6] M. W. Ross, Pedagogy for prisoners: an approach to peer health education for inmates, J Correct Health Care, Vol.17, No.1, 6-18, 2011.

[7] C. Coleman, S. Kurtz-Rossi, J. McKinney, A. Pleasant, I. Rootman, L. Shohet, The Calgary Charter on Health Literacy :Rationale and Core Principles for the Development of Health Literacy Curricula, Montreal, 2008.

[8] I. Rootman, D. A. Gordon-EL-Bihbety, Vision for a Health Literate Canada: Report of the Expert Panel on Health Literacy, Ottawa, ON, 2008.

[9] T. C. Davis, M. V. Williams, E. Marin, R. M. Parker, J. Glass, Health literacy and cancer communication, CA Cancer J Clin, Vol.52, No.3, 134-149, 2002.

[10] D. Nutbeam, The evolving concept of health literacy, Soc Sci Med, Vol.67, No.12, 2072-2078, 2008. 
[11] Statistics Canada. Skills in Canada: First Results from the Program for the International Assessment of Adult Competencies [PIAAC], Ottawa, ON, 2013.

[12] Canadian Council on Learning. Health literacy in Canada: A healthy understanding, 1-36, 2008.

[13] W. Mitic, I. Rootman, An inter-sectoral approach for improving health literacy for Canadians, 2012.

[14] K. Viswanath, L. K. Ackerson, Race, ethnicity, language, social class, and health communication inequalities: A nationally-representative cross-sectional study. PLoS One, Vol.6, No.1, e14550, 2011.

[15] K. Viswanath, Public communications and its role in reducing and eliminating health disparities. In: G. E. Thomson, F. Mitchell, M. B. Williams, editors. Examining the Health Disparities Research Plan of the National Institutes of Health, Washington, DC, Unfinished Business. Institute of Medicine, 215-253, 2006

[16] M. K. Paasche-Orlow, M. S. Wolf, Promoting health literacy research to reduce health disparities, J Health Commun, Vol. 15 Suppl.2 No.932223628, 34-41, 2010.

[17] L. Donelle, L. Hoffman-Goetz, Health literacy and online health discussions of North American Black women, Women Health, Vol. 47, No.4, 71-90, 2008.

[18] C. Robinson, J. Graham, Perceived Internet health literacy of HIV-positive people through the provision of a computer and Internet health education intervention, Health Info Libr J, Vol. 27, No. 4, 295-303, 2010.

[19] R. Squellati, Health Literacy: Understanding Basic Health Information, Creat Nurs, Vol.16, No.3, 110-114, 2010.

[20] K. Viswanath, M. W. Kreuter, Health disparities, communcation inequalities, and e-health: A commentary, Clin Adv Hematol Oncol, Vol. 32, No.5, 131-133, 2007.

[21] S. Fox, M. Duggan, Health Online 2013, Washingtion, DC, 2013.

[22] Statistics Canada. 2009 Canadian Internet Use Survey, Ottawa, ON, 2011

[23] N. Mcinnes, B. J. Haglund, Readability of online health information: implications for health literacy Informatics Heal Soc Care, Vol.36, No.4, 173-189, 2011.

[24] B. A. Moloughney, Health care needs assessment of federal prisoners, Can J Public Heal, Vol.95, Suppl.1, 1-63, 2004.

[25] E. Greenberg, E. Dunleavy, M. Kutner, Literacy behind bars: Results from the 2003 National Assessment of Adult Literacy Prison Survey, 2007.

[26] J. A. Cohen, Power primer. Psychol Bull, Vol.112, No.1, $155-159,1992$.

[27] E. Waltermaurer, Convenience sample. In: S. Boslaugh, editor. Encyclopedia of epidemiology. Thousand Oaks, CA, Sage Publications, 236, 2008.

[28] B. D. Weiss, M. Z. Mays, W. Martz, K. M. Castro, D. A. DeWalt, M. P. Pignone, et al, Quick assessment of literacy in primary care: The Newest Vital Sign. Ann Fam Med, Vol.3, No.6, 514-522, 2005.

[29] IBM. SPSS Statistics for Windows, version 22.0. Armonk,
NY, IBM Corp, 2013.

[30] Donelle, J. Hall, S. Benbow, A case study of the health literacy of a criminalized woman. Int J Heal Promot Educ, Vol.53, No.4, 192-203, 2015.

[31] B. L. Green, J. Miranda, A. Daroowalla, J. Siddique. Trauma exposure, mental health functioning, and program needs of women in jail, Crime \& Delinquency, Vol.51, No.1, 133-151, 2005.

[32] T. J. Conklin, T. Lincoln, R. W. Tuthill. Self-reported health and prior health behaviors of newly admitted correctional inmates. American Journal of Public Health, Vol.90, No.12, 1939, 2000.

[33] J. R. Bernier, MacLellan. Health status and health services use of female and male prisoners in provincial jail. 2011. Online Available from www.acewh.dal.ca.

[34] B. W. Hesse, D. E. Nelson, G. L. Kreps, R. T. Croyle, N. K. Arora, B. K. Rimer, K. Viswanath. Trust and source of health information: The impact of the internet and its implications for health care providers: Findings from the first health information nations trends survey. Archives of Internal Medicine, Vol.165, No.22, 2618-2624, 2005.

[35] M. Berger, T. H. Wagner, L. C. Baker. Internet use and stigmatized illness. Social Science \& Medicine, Vol.61, No.8, 1821-1827, 2005.

[36] J. W. Frank, E. A. Wang, M. Nunez-Smith, H. Lee, M. Comfort. Discrimination based on criminal record and healthcare utilization among men recently released from prison: A descriptive study. Health \& Justice, Vol.2, No.1, 6, 2014.

[37] S. P. Kulkarni, S. Baldwin, A. S. Lightstone, L. Gelberg, A. L. Diamant. Is incarceration a contributor to health disparities? Access to care of formerly incarcerated adults. Journal of Community Health, Vol.35, No.3, 268-74, 2010.

[38] M. Zrinyi, Z. Balogh. Student nurse attitudes towards homeless clients: A challenge for education and practice. Nursing Ethics, Vol.11, No.4, 2004.

[39] R. J. W. Cline, K. M. Haynes. Consumer health information seeking on the Internet: The state of the art. Health Education Research, Vol.16, No.6, 671-692, 2001.

[40] Canadian Council on Learning. Health literacy in Canada: Initial results from the international adult literacy and life skills survey. Ottawa, ON: OECD and Statistics Canada, 2007. Online available from

http://www.ccl-cca.ca/pdfs/HealthLiteracy/HealthLiteracyin Canada.pdf

[41] D. B. Friedman, L. Hoffman-Goetz, J. F. Arocha. Readability of cancer information on the internet. Journal of Cancer Education: The Official Journal of the American Association for Cancer Education, Vol.19, No.2, 117-22, 2004.

[42] London Area Wireless Network (LAWN). What is London LAWN? 2014. Online available from http://www.londonlawn.ca/

[43] N. Diviani, B. van den Putte, S. Giani, J. C. M. van Weert, Low health literacy and evaluation of online health information: A systematic review of the literature. J Med Internet Res, Vol. 17, No. 5, e112, 2015. 